
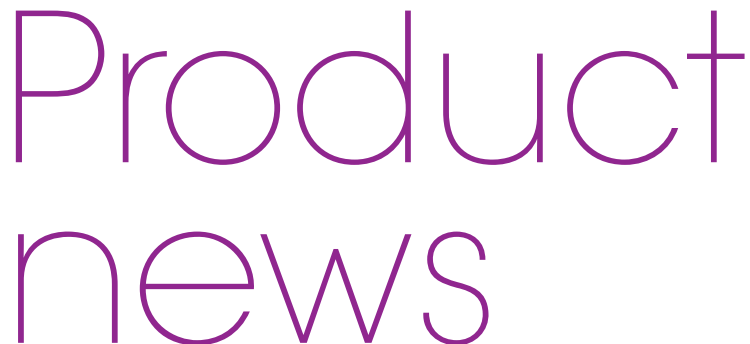

Product news is provided as a service to readers using text and images from

the manufacturer, supplier or distributor and does not imply endorsement

by BDJ Team. Normal and prudent research should be exercised before

purchase or use of any product mentioned.

\section{FOR VISIBLY WHITERTEETH}

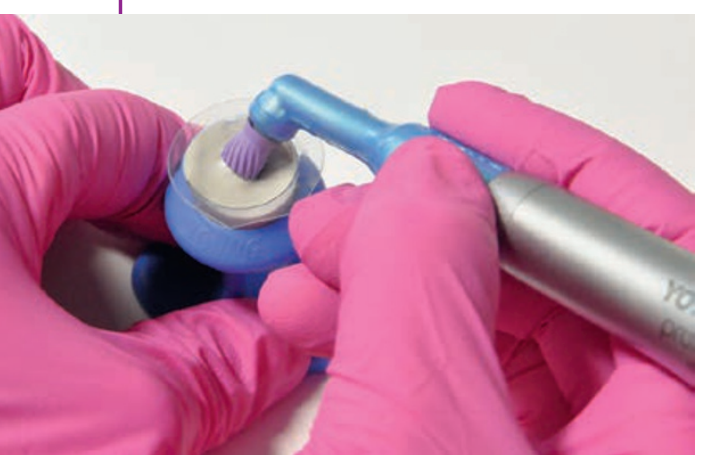

Young Dental presents a range of new pastes for professional teeth cleaning. They remove discoloration, achieve significant teeth whitening, and impress with their remarkable efficiency. The $\mathrm{pH}$-neutral pastes are less abrasive than similar products, so have a particularly gentle feel, and are vegan as well as sugar-, lactose- and gluten-free.

The 'mint' and 'berry' varieties are supplied in single doses, and come with a handy finger-ring holder.The hygienic disposable packaging minimises the risk of cross-contamination. A fluoride-free polishing paste with fine granulation and a stain remover in medium granulation with $1.23 \%$ fluoride are available. To reduce splatter, Young Dental has developed an especially adhesive consistency for the pastes.

Xylitol reduces the development of plaque and tooth-damaging acids and has a proven cariostatic and even anti-cariogenic effect. Natron shortens the cleaning time and enhances teeth whitening. It also improves the buffering capacity of saliva and removes harmful microorganisms in plaque. Thanks to the acid-neutralising effect, the growth of caries bacteria is slowed.

Young Innovations is a leading developer, manufacturer and retailer of high-quality dental products.

www.youngdental.eu

\title{
BE READY FOR ANY EMERGENCY
}

Seek out the Zoll AED Plus when you need to take action to save a life.

Available from Dental Express (a trading division of Surgery Express LLP), the Zoll AED Plus is the only automatic external defibrillator that can track your movements as you apply CPR.

Featuring a unique feedback system, the Zoll AED Plus is able to monitor the quality of CPR and provide real-time feedback of depth and rate of chest compressions. The audio and visual prompts of the device help guide you through the process so you can be confident in your rescue.

The durable design of the Zoll AED Plus is dust- and water-resistant, and comes with a 5-year warranty to give you peace of mind. Powerful lithium batteries and automatic self-testing ensure this AED is ready for any emergency at any time.

Trust in the Zoll AED Plus to save lives in your practice. Plus, you'll benefit from the specialist support of Dental Express and a next-day delivery guarantee.

For more information, visit www.dentalexpress.co.uk, call 08007076212 or email sales@dental-express.co.uk.

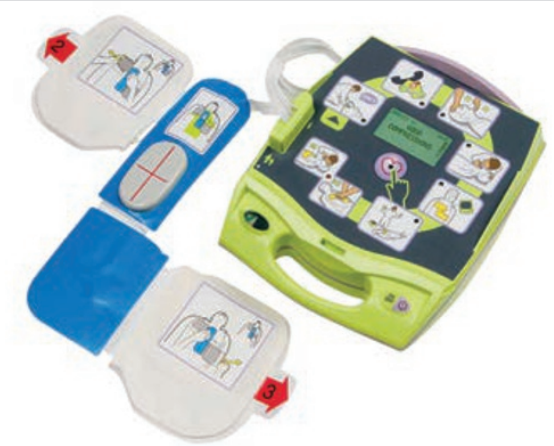

ALL THE BENEFITS WITHOUT THE SIDE EFFECTS

For the benefits of chlorhexidine without common side effects such as discoloration, irritation and impairment of taste, recommend CURASEPT ADS

(Anti-Discoloration System) to your patients.

The CURASEPT ADS 205 oral rinse combines $0.05 \%$ chlorhexidine digluconate and $0.05 \%$ sodium fluoride for ultimate plaque control and prevention of caries and gingivitis. It's also ideal for patients with impaired motor skills.

Other rinses using the AntiDiscoloration System available from Curaprox can be used before and after mouth operations, as preparation for chemo- and radiation therapy and as a toothpaste replacement with orthodontic devices. CURASEPT ADS not only ensures high tolerance and acceptance, but can significantly reduce inflammation, plaque, bleeding and dental pigmentation, and help to accelerate wound healing and minimise post-surgery complications.

To get the best results for your patients, try recommending CURASEPT ADS from Curaprox.

For more information call 01480 862084, email info@curaprox.co.uk or visit www.curaprox.co.uk.

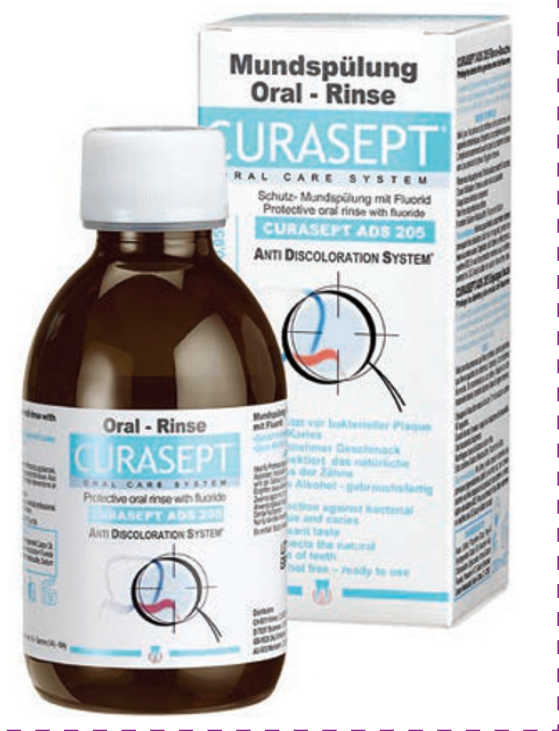

If you would like to promote your products or services direct to the dental industry in BDJ Team, call Andy May on 02078434785 or emaila.may@nature.com. 